\title{
The variant selection criteria in single-crystal CuAINi shape memory alloys
}

\author{
X Y Zhang $\dagger$, L C Brinson $\dagger \S$ and Q P Sun $\ddagger$ \\ $\dagger$ Mechanical Engineering Department, 2145 Sheridan Rd, Northwestern University, \\ Evanston, IL 60208, USA \\ $\ddagger$ Department of Mechanical Engineering, The Hong Kong University of Science \& \\ Technology, Clear Water Bay, Kowloon, Hong Kong SAR, People's Republic of China
}

Received 16 September 1999

\begin{abstract}
Two variant selection criteria are often used in shape memory alloys (SMAs). One is the maximum resolved shear stress (RSS) criterion and the other is the maximum transformation work criterion. In this paper these two measures are calculated using the crystallographic theory of martensite (CTM) for the shape memory effect (SME) case and the crystallographic theory of martensite + detwinning, distortion and slip (CTM + DDS) for the superelasticity (SE) case. The results are compared with the experimental measurements of a CuAlNi single-crystal SMA. The comparisons show that work is better as a variant selection criterion than RSS. In the SME case, type-II twin variants are more favorable under uniaxial tension; while type-I twin variants are more favorable under uniaxial compression. The calculation also shows that a great tension-compression asymmetry exists in CuAlNi single crystals.
\end{abstract}

\section{Introduction}

Shape memory alloys (SMAs) are known to exhibit special properties, such as the shape memory effect (SME) and superelasticity (SE). The underlying mechanism of these properties is the martensitic transformation, which is a displacive, diffusionless and reversible phase transformation. To date, there are nearly 20 alloys which show shape memory properties and the NiTi-based SMAs are the most important for practical use (Funakubo 1984). NiTi alloy materials exhibit high strength, ductility and resistance to corrosion in addition to excellent SME characteristics. However, $\mathrm{NiTi}$ alloys are significantly more expensive than $\mathrm{Cu}$-based SMAs. Further advantages for $\mathrm{Cu}$-based alloys include processability and ease of growth for the bulk single crystal. Therefore many research efforts have focused on $\mathrm{Cu}$-based SMAs, such as $\mathrm{CuAl}, \mathrm{CuZnAl}, \mathrm{CuAlNi}$, etc. In this paper the attention is concentrated on CuAINi single-crystal SMAs.

Research on CuAlNi single-crystal SMAs has focused on three major aspects (see figure 1): experiments on the stress-induced martensitic transformation, theories on the martensitic transformations and constitutive models of the transformation-induced plasticity. Experiments on the stressinduced martensitic transformation have been performed at three levels: (1) the macroscopic properties of the SMAs, such as the macroscopic stress-strain relationship under different temperatures and orientations (Oishi and Brown 1971, Otsuka et al 1976, 1979; Saburi and Nanno 1981);

$\S$ Author to whom all correspondence should be addressed.
(2) the microstructure determination of the parent phase and the different martensitic variants by using TEM, SEM, X-rays, etc (Otsuka and Shimizu 1969, 1974b, Otsuka et al 1974, Ichinose et al 1985, Okamoto et al 1986, Horikawa et al 1988); and (3) the micro-macro-related deformation measurement by using high-resolution moiré interferometry (Sun et al 1999a, b, Zhang et al 1999, 2000).

From these experimental results, we have obtained the following picture of CuAlNi SMAs: the nature of the stressinduced martensitic transformation is strongly dependent on the test temperature as well as the loading axis orientation. At a temperature near $M_{s}$, the stress-induced martensitic transformation is from the $\mathrm{DO}_{3} \beta_{1}$-phase to the $2 \mathrm{H} \gamma_{1}^{\prime}$ phase. Part or all of these martensitic variants will remain after unloading and only upon heating does the reverse transformation occur. In this case the material exhibits the SME. When the temperature is above $A_{f}$, the stress-induced martensite is the $18 \mathrm{R} \beta_{1}^{\prime}$-phase. These martensitic variants will disappear immediately after the removal of the stress and they are described as pseudoelastic (or superelastic, SE). The interface between the martensite and the parent phase was visually verified as an invariant plane in the transformation from $\beta_{1}$ to $\gamma_{1}^{\prime}$ (Zhang et al 1998, 1999, 2000), while in the transformation from $\beta_{1}$ to $\beta_{1}^{\prime}$, the interfaces were found to be in a non-invariant plane (Sun et al 1999a, b, Zhang et al 2000).

There are two major habit-plane-based theories for the martensitic transformation: the phenomenological theory of martensite crystallography (PTMC, Wechsler et al 1953, 


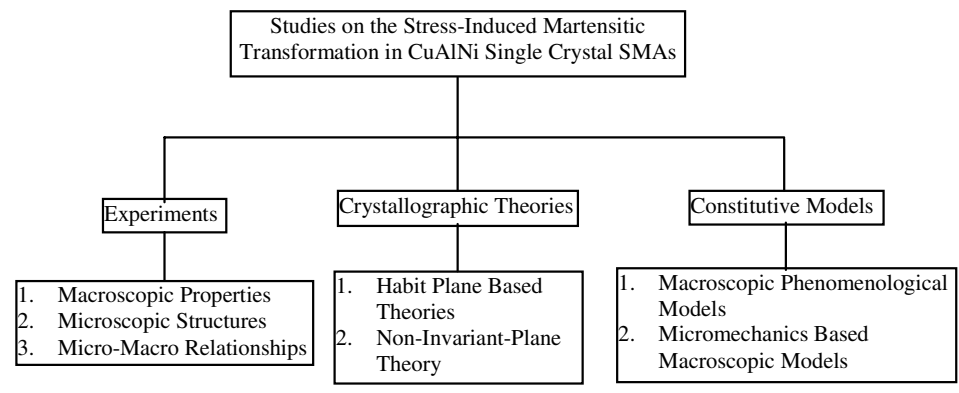

Figure 1. A sketch of the research work on CuAlNi SMAs.

Bowles and Mackenzie 1954, Khachaturyan 1983) and the crystallographic theory of martensite (CTM, Ball and James 1987). The key point of the theories is to construct the invariant interface between the austenite and the martensite (A-M interface). These two theories have been applied in single-crystal CuAlNi SMAs; the theoretical predictions agreed well with the experimental measurements when the $\mathrm{A}-\mathrm{M}$ interface was an invariant plane in the transformation from $\beta_{1}$ to $\gamma_{1}^{\prime}$ in the SME case (Okamoto et al 1986, Bhattacharya 1991, Chu 1993, Shield 1995, Zhang et al 1999, 2000). For the martensitic transformation from $\beta_{1}$ to $\beta_{1}^{\prime}$, the A-M interface is no longer an invariant plane. The CTM+DDS model, which is not based on the invariant plane, showed good agreement with the experimental measurements (Zhang et al 2000).

The constitutive models can be divided into two major categories. The first one contains the macroscopic phenomenological models. These are built on phenomenological thermodynamics and/or directly curve fitting experimental data. The volume fraction of the martensite is typically used as the internal variable and different mathematical functions are used to describe the transformation procedure (Sato and Tanaka 1988, Liang and Rogers 1990, 1992, Boyd and Lagoudas 1994, Bekker and Brinson 1997). Most of the models in this group only work on uniaxial loading or are simple yet unverified extensions of these models to $3 \mathrm{D}$. The second category contains the micromechanics-based macroscopic models. These use thermodynamics laws to describe the transformation and micromechanics to estimate the interaction energy due to the transformation in the material, which is a key factor in the transformation mechanism (Patoor et al 1993, 1994, Sun and Hwang 1993a, b, Goo and Lexcellent 1997, Lu and Wang 1997, Huang and Brinson 1998, Gao and Brinson 2000).

A common interesting issue in these three research areas is understanding the driving force of the stressinduced martensitic transformation. This problem has a special meaning in model development since the fundamental element of any model is to appropriately identify when the phase transformation starts, which variant appears and when reorientation happens. According to the crystallographic theory there are 96 possible habit-plane variants for the $\beta_{1}$ to $\gamma_{1}^{\prime}$ martensitic transformation in CuAlNi SMAs (Shield 1995, Zhang et al 1999, 2000). Among these, 48 are habit-plane variants with a type-I twin, and another 48 are with a type-II twin. It is still not very clear which variant will appear first under a certain applied stress. In the earlier literature, it was

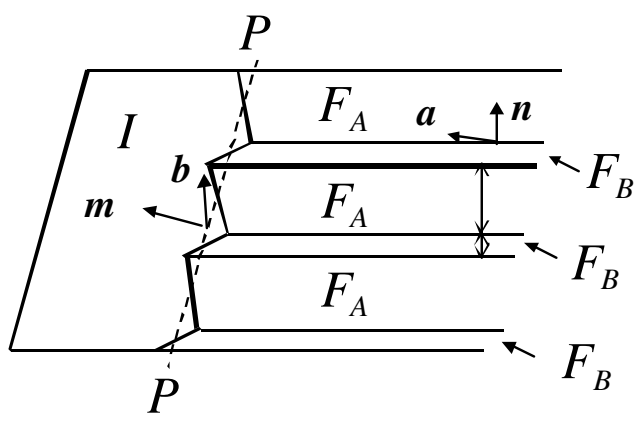

Figure 2. A schematic graph of the $\gamma_{1}^{\prime}$ martensite (seen in the SME).

reported that the variants with a type-I twin were preferential under applied stress (Otsuka and Shimizu 1969, 1974a). In some later papers, the type-II twin was determined to be the lattice invariant shear by using two surface analyses$\mathrm{X}$-ray diffraction and the scratch technique (Ichinose et al 1985, Okamoto et al 1986). Recently it was found that the variants with both type-I and type-II twin were possible by a comprehensive comparison of the transformation strains and the A-M interface normals (Zhang et al 1998, 1999, 2000). In this paper, a systematic analysis of the driving force will be given. In section 2 , the theoretical calculations using both the crystallographic theory of martensite for the $\beta_{1}$ to $\gamma_{1}^{\prime}$-phase transformation and the non-invariant-plane model for the $\beta_{1}$ - to $\beta_{1}^{\prime}$-phase transformation are reported. Two different types of driving force-the resolved shear stress and the maximum transformation work-are introduced in section 3. In section 4, an experimental verification of the driving force using our moiré results is given. The results are discussed in section 5 .

\section{The theoretical calculations}

\subsection{On the transformation from $\beta_{1}$ to $\gamma_{1}^{\prime}$}

The microstructure of the $\gamma_{1}^{\prime}$ martensite in a CuAlNi single crystal is schematically illustrated in figure 2 . The martensitic habit-plane variant is composed of two lattice correspondence variants which have a twin relationship. The vectors $\boldsymbol{m}$ and $\boldsymbol{n}$ are, respectively, the normals of the habit-plane (plane $P-P$ ) and the twin-plane, $\boldsymbol{a}$ and $\boldsymbol{b}$ are the vectors of the twinning shear and transformation shear, respectively. $\boldsymbol{F}_{A}$ and $\boldsymbol{F}_{B}$ are the deformation gradient matrices of the two lattice correspondence variants and $\boldsymbol{I}$ is the deformation 


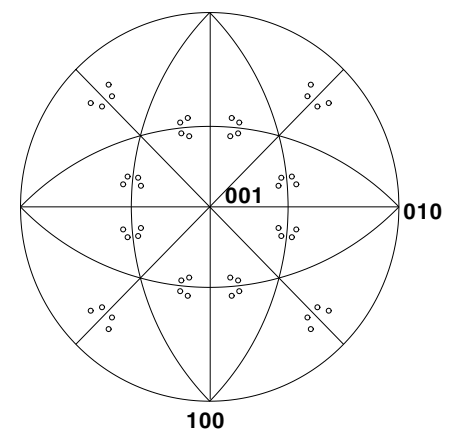

Habit Planes of Type I Twin Variants

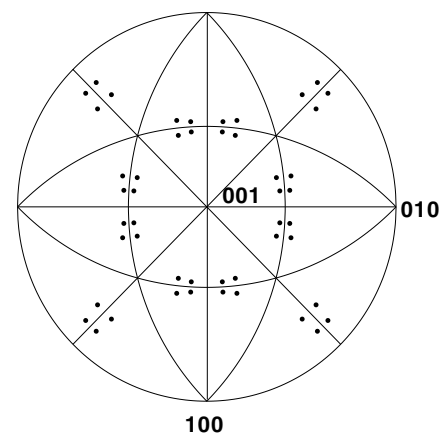

Habit Planes of Type II Twin Variants

Figure 3. The directions of the habit-plane represented in a stereographic projection.

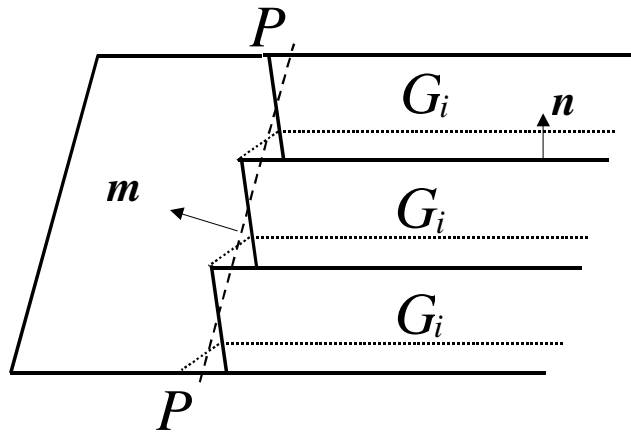

Figure 4. A schematic graph of the $\beta_{1}^{\prime}$ martensite (seen in pseudoelasticity).
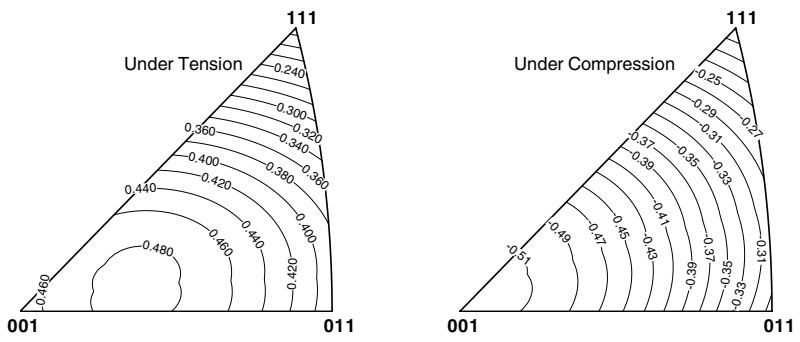

Figure 5. Contours of maximum RSS under uniaxial stresses in different directions.

matrix of the parent phase (because all these quantities are determined with respect to the parent phase). The volume fractions of the two lattice correspondence variants $A$ and $B$ in the twin are $1-f$ and $f$, respectively.

The CTM (Ball and James 1987) is used to calculate the habit-plane normal and the transformation strains. In this theory two types of invariant plane were considered. The first one is the interface between the two lattice correspondence variants in the twin; and the second one is the interface between the martensite and the parent phase (the habit-plane). The compatibility conditions for these two invariant planes are, respectively (Ball and James 1987, Bhattacharya 1992),

Twin-plane:

$$
\boldsymbol{F}_{A}-\boldsymbol{F}_{A}=\boldsymbol{a} \otimes \boldsymbol{n}
$$

Habit-plane:

$$
\boldsymbol{R}_{h} \cdot\left[f \boldsymbol{F}_{B}+(1-f) \boldsymbol{F}_{A}\right]-I=\boldsymbol{b} \otimes \boldsymbol{m}
$$

where $\boldsymbol{R}_{h}$ is a rigid rotation; and

$$
\boldsymbol{F}^{M}=\boldsymbol{R}_{h} \cdot\left[f \boldsymbol{F}_{b}+(1-f) \boldsymbol{F}_{A}\right]
$$

represents the average deformation gradient of the twinned martensite. The polar decomposition of a deformation gradient, for example $\boldsymbol{F}_{A}$, is

$$
\boldsymbol{F}_{A}=\boldsymbol{R}_{A} \cdot \boldsymbol{U}_{A}
$$

where $\boldsymbol{R}_{A}$ is a rigid rotation and $\boldsymbol{U}_{A}$ is a pure stretch. Without losing any generality, equation (1) can be rewritten as

$$
\boldsymbol{R}_{A B} \cdot \boldsymbol{U}_{B}-\boldsymbol{U}_{A}=\boldsymbol{a} \otimes \boldsymbol{n}
$$

where $\boldsymbol{R}_{A B}$ is an orthogonal tensor and represents the relative rotation between the two variants in the twin. $\boldsymbol{U}_{A}$ and $\boldsymbol{U}_{B}$ are the symmetric parts of $\boldsymbol{F}_{A}$ and $\boldsymbol{F}_{B}$ respectively. In $\mathrm{CuAlNi}$ single-crystal SMA, there are six independent stretch $U$ 's corresponding to the six lattice correspondences between the cubic $\beta_{1}$-phase and the orthorhombic $\gamma_{1}^{\prime}$ phase. So in equations (1)-(5) $A$ and $B$ are the integers $\{1,2, \ldots, 6\}$.

Equations (2) and (3) can also be written as

$$
\begin{gathered}
\boldsymbol{R}_{h} \cdot\left(\boldsymbol{U}_{A}+f \boldsymbol{a} \otimes \boldsymbol{n}\right)-\boldsymbol{I}=\boldsymbol{b} \otimes \boldsymbol{m} \\
\boldsymbol{F}^{M}=\boldsymbol{R}_{h} \cdot\left[\boldsymbol{U}_{A}+f \boldsymbol{a} \otimes \boldsymbol{n}\right]
\end{gathered}
$$

or

$$
\begin{aligned}
\boldsymbol{F}^{M} & =\boldsymbol{R}_{h} \cdot\left[\boldsymbol{I}+f \boldsymbol{a} \otimes \boldsymbol{n} \cdot \boldsymbol{U}_{A}^{-1}\right] \cdot \boldsymbol{U}_{A} \\
& =\boldsymbol{R}_{h} \cdot \boldsymbol{S}_{\gamma_{1}^{\prime}} \cdot \boldsymbol{U}_{A} .
\end{aligned}
$$

Here the rigid rotation $\boldsymbol{R}_{h}$ is different from that in equation (2). Equation (8) has a form similar to those in the phenomenological theory of martensite crystallography (Wechsler et al 1953, Bowles and Mackenzie 1954). The three terms of $\boldsymbol{R}_{h}, \boldsymbol{S}_{\gamma_{1}^{\prime}}$ and $\boldsymbol{U}_{A}$ represent rigid rotation, the twinning shear and the stretch of the lattice structure, respectively. The input of equations (5)-(8) is $\boldsymbol{U}_{A}$ and $\boldsymbol{U}_{B}$, which are determined from the lattice structures and lattice parameters of austenite and martensite. Equation (5) gives $\boldsymbol{a}, \boldsymbol{n}$ and $\boldsymbol{R}_{A B}$. Substituting $\boldsymbol{a}$ and $\boldsymbol{n}$ into equation (6), the volume fraction $f$, habit-plane normal $\boldsymbol{m}$, transformation shear $\boldsymbol{b}$ and rigid rotation $\boldsymbol{R}_{h}$ are obtained. There are 12 combinations of $A$ and $B$ in equation (5) ([1, 3], [1, 4], [1, 5], $[1,6],[2,3],[2,4],[2,5],[2,6],[3,5],[3,6],[4,5],[4,6])$, 


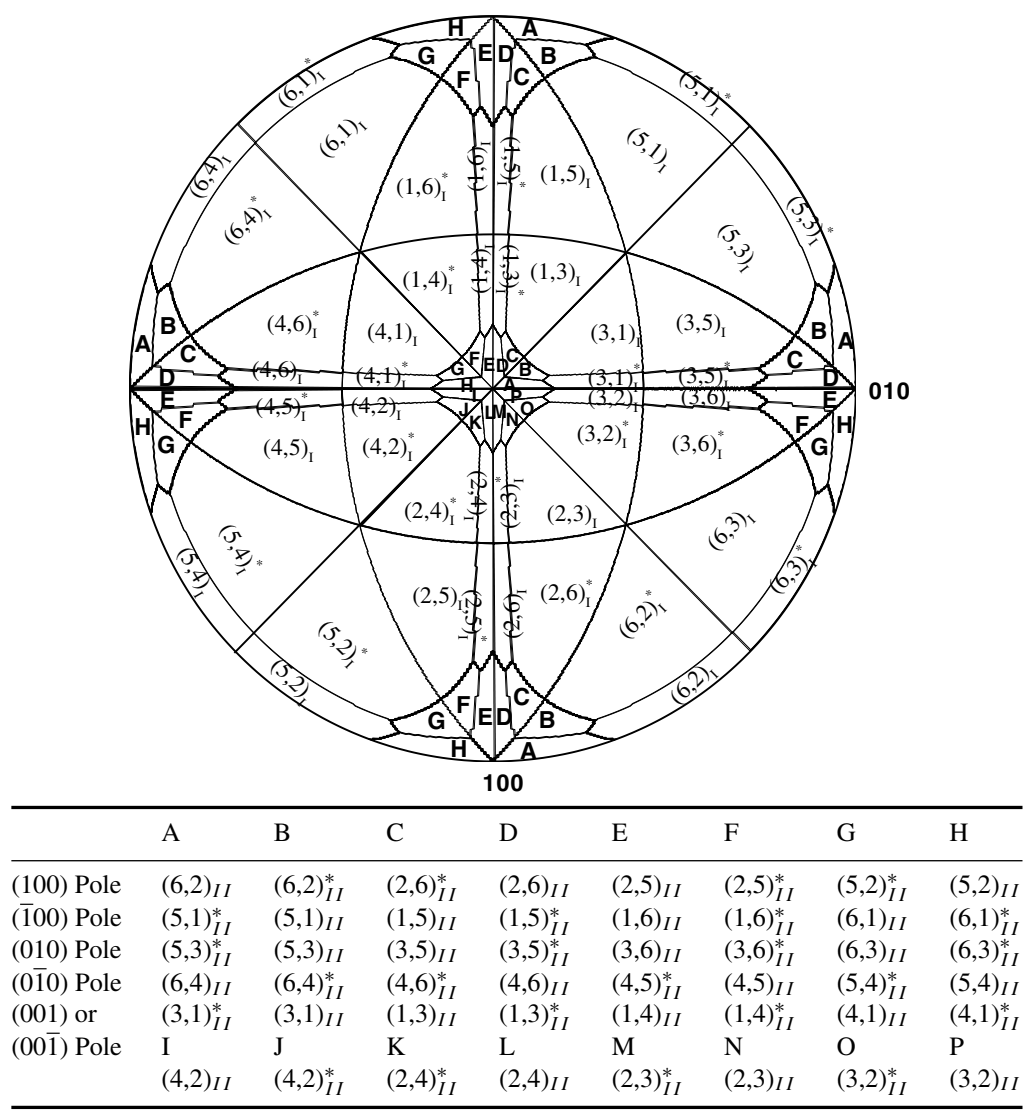

(a)
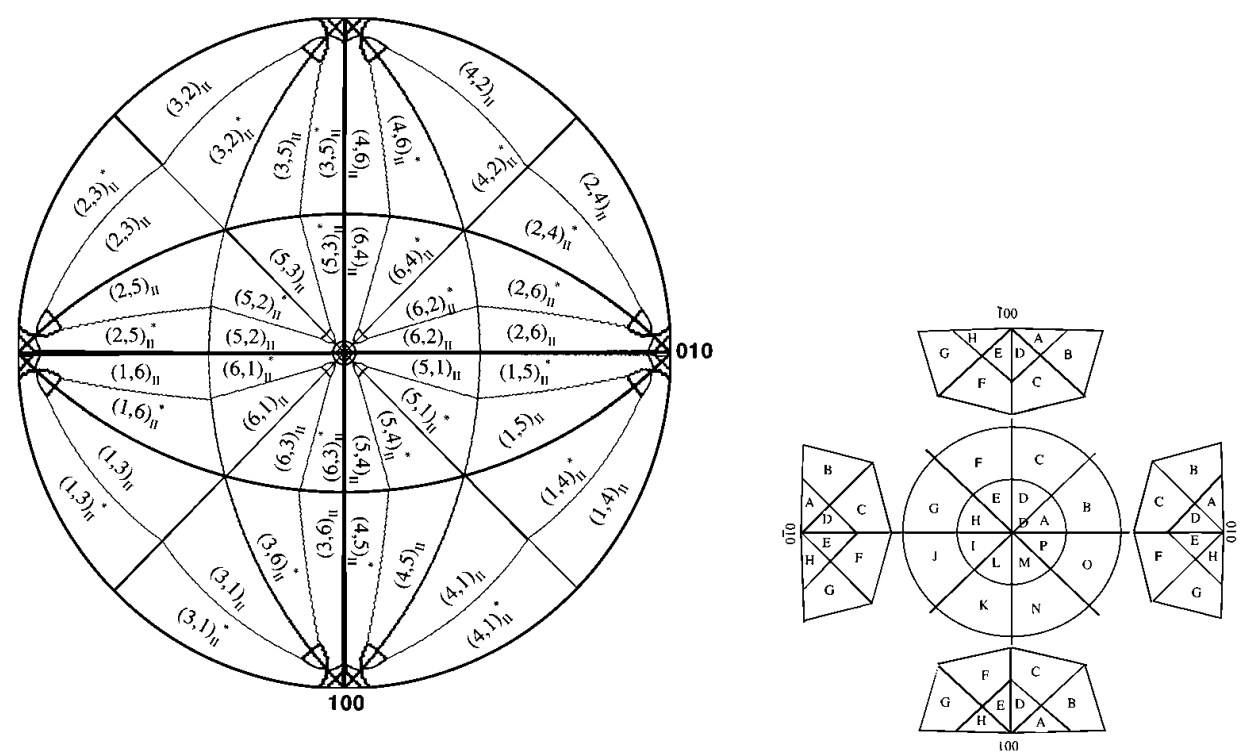

\begin{tabular}{lllllllll}
\hline & $\mathrm{A}$ & $\mathrm{B}$ & $\mathrm{C}$ & $\mathrm{D}$ & $\mathrm{E}$ & $\mathrm{F}$ & $\mathrm{G}$ & $\mathrm{H}$ \\
\hline$(100)$ Pole & $(4,1)_{I}$ & $(4,1)_{I}^{*}$ & $(4,5)_{I}^{*}$ & $(4,5)_{I}$ & $(3,6)_{I}$ & $(3,6)_{I}^{*}$ & $(3,1)_{I}^{*}$ & $(3,1)_{I}$ \\
$(\overline{1} 00)$ Pole & $(4,2)_{I}^{*}$ & $(4,2)_{I}$ & $(4,6)_{I}$ & $(4,6)_{I}^{*}$ & $(3,5)_{I}$ & $(3,5)_{I}^{*}$ & $(3,2)_{I}$ & $(3,2)_{I}^{*}$ \\
$(010)$ Pole & $(2,4)_{I}^{*}$ & $(2,4)_{I}$ & $(2,6)_{I}$ & $(2,6)_{I}^{*}$ & $(1,5)_{I}$ & $(1,5)_{I}^{*}$ & $(1,4)_{I}$ & $(1,4)_{I}^{*}$ \\
$(0 \overline{1} 0)$ Pole & $(2,3)_{I}$ & $(2,3)_{I}^{*}$ & $(2,5)_{I}^{*}$ & $(2,5)_{I}$ & $(1,6)_{I}^{*}$ & $(1,6)_{I}$ & $(1,3)_{I}^{*}$ & $(1,3)_{I}$ \\
$(001)$ or & $(6,2)_{I}^{*}$ & $(6,2)_{I}$ & $(6,4)_{I}$ & $(6,4)_{I}^{*}$ & $(5,3)_{I}$ & $(5,3)_{I}^{*}$ & $(5,2)_{I}^{*}$ & $(5,2)_{I}$ \\
$(00 \overline{1})$ Pole & $\mathrm{I}$ & $\mathrm{J}$ & $\mathrm{K}$ & $\mathrm{L}$ & $\mathrm{M}$ & $\mathrm{N}$ & $\mathrm{O}$ & $\mathrm{P}$ \\
& $(6,1)_{I}$ & $(6,1)_{I}^{*}$ & $(6,3)_{I}^{*}$ & $(6,3)_{I}$ & $(5,4)_{I}^{*}$ & $(5,4)_{I}$ & $(5,1)_{I}$ & $(5,1)_{I}^{*}$ \\
\hline
\end{tabular}

(b)

Figure 6. The most favorable variants under uniaxial stresses in different directions using the RSS criterion; same for SME and SE cases: (a) under tension; (b) under compression. 
and each pair can form either a type-I twin or a type-II twin. So there are 24 twinning systems $\left(\boldsymbol{a}_{i}, \boldsymbol{n}_{i}\right)(i=1,2, \ldots, 24)$ in $\gamma_{1}^{\prime}$ martensite. The type-I and -II twins are defined as follows: a type-I twin has rational twin-planes and irrational twinning shear directions in the cubic basis, while a type-II twin has irrational twin-planes and rational twinning shear directions. Substituting each twinning system ( $\boldsymbol{a}$ and $\boldsymbol{n}$ ) into equation (6), two solutions for the volume fraction $f$, are obtained, for each of which equation (6) provides two possible sets of solutions for $\boldsymbol{R}_{h}, \boldsymbol{b}$ and $\boldsymbol{m}$. Therefore, in total, 96 possible habit-plane variants can be obtained. See the references for more detailed discussion (Shield 1995, Zhang et al 1999, 2000). The position of the 96 habit-planes in the stereographic projection is shown in figure 3.

\subsection{On the transformation from $\beta_{1}$ to $\beta_{1}^{\prime}$}

The $\mathrm{A}-\mathrm{M}$ interface in the $\beta_{1}$ to $\beta_{1}^{\prime}$ martensitic transformation was found to be a non-invariant plane by use of highresolution moiré interferometry (Sun et al 1999a, b, Zhang et al 2000). As a result, calculation of the A-M interface direction and transformation strain must be modified from the CTM method. Here we employ a recently proposed crystallographic model (Zhang et al 2000).

A sketch of the microstructure of $\beta_{1}^{\prime}$ martensite is delineated by the full lines in figure 4 . This is a singlecrystal variant with stacking faults (Otsuka et al 1974, 1979, Horikawa et al 1988). $\boldsymbol{G}_{i}$ is the lattice deformation of $\beta_{1}^{\prime}$ martensite. There are 12 such matrices (annotated as $\boldsymbol{G}_{1}$, $\boldsymbol{G}_{1^{\prime}}, \boldsymbol{G}_{2}, \boldsymbol{G}_{2^{\prime}}, \ldots, \boldsymbol{G}_{6}$ and $\left.\boldsymbol{G}_{6^{\prime}}\right)$ which correspond to the 12 lattice correspondence variants in $\beta_{1}^{\prime}$ martensite. Plane $P-P$ is the macroscopic interface between austenite and martensite and $\boldsymbol{m}$ is its normal. Vector $\boldsymbol{n}$ is the normal of simple shear plane which is the same as the twin-plane in $\gamma_{1}^{\prime}$ martensite (the dotted lines in the figure represent the traces of the twin).

In a similar way as that used for equation (4), the lattice deformation $\boldsymbol{G}_{i}$ and $\boldsymbol{G}_{i^{\prime}}$ in $\beta_{1}^{\prime}$ martensite can be decomposed as

$$
G_{i}=R_{i} \cdot V_{i} \quad G_{i^{\prime}}=R_{i^{\prime}} \cdot V_{i^{\prime}}
$$

where $R_{i}$ and $R_{i^{\prime}}$ are rigid rotations and have the same value as $R_{A}$ in equation (4) when $A$ and $i$ are the same integer. $V_{i}$ and $V_{i}$ are the pure stretches of the martensite but are not symmetric matrices.

Comparing this with the structure of the twinned $\gamma_{1}^{\prime}$ martensite in figure 2 , we assume that this martensite is a product of detwinning (the minor variant changes into the major variant in the $\gamma_{1}^{\prime}$ twin so the twinned $\gamma_{1}^{\prime}$ changes into the stacking faulted $\beta_{1}^{\prime}$ ), lattice distortion (orthorhombic $\gamma_{1}^{\prime}$ changes to monoclinic $\beta_{1}^{\prime}$, i.e. $U_{i}$ changes to $V_{i}$ ) and slip shear (lattice invariant shear). This procedure can be annotated as DDS (Detwinning + Distorting + Slip). Let the slip shear in the $\beta_{1}^{\prime}$ martensite be equivalent to the twinning shear in the $\gamma_{1}^{\prime}$ martensite in three aspects: the slip plane, the slip direction and the magnitude of the slip shear. These three steps determine the direction of the $\mathrm{A}-\mathrm{M}$ interface in $\beta_{1}^{\prime}$ to be the same as that of the habit-plane in $\gamma_{1}^{\prime}$. The $96 \mathrm{~A}-\mathrm{M}$ interfaces between the parent phase and the $\beta_{1}^{\prime}$ martensite are also presented in figure 3 .
For the transformation strain of the $\beta_{1}^{\prime}$ martensite, the average deformation gradient $G^{M}$ can be written in the same form as equation (8),

$$
\boldsymbol{G}^{M}=\boldsymbol{R}_{h} \cdot \boldsymbol{S}_{\beta_{1}^{\prime}} \cdot V_{i}
$$

where $\boldsymbol{R}_{h}$ is the same as that in $\gamma_{1}^{\prime}$ martensite. The lattice invariant shear is

$$
\boldsymbol{S}_{\beta_{1}^{\prime}}=\boldsymbol{I}+f \boldsymbol{a} \otimes \boldsymbol{n} \cdot \boldsymbol{V}_{i}^{-1}
$$

This is represented in the reference configuration with respect to the $\beta_{1}^{\prime}$ martensite which has a deformation of $\boldsymbol{V}_{i}$. In the parent phase reference, the slip plane and the slip vector of $\boldsymbol{S}_{\beta_{1}^{\prime}}$ are, respectively, $\boldsymbol{n}$ and $\boldsymbol{a}$ which are the same as the twinplane and twinning shear in $\gamma_{1}^{\prime}$ martensite. The difference in the transformation strain between the $\gamma_{1}^{\prime}$ and $\beta_{1}^{\prime}$ martensite is in the stretch of the lattice structure. These stretches are determined by the lattice correspondence of the martensite. There are six independent lattice correspondence variants in $\gamma_{1}^{\prime}$ martensite and 12 in $\beta_{1}^{\prime}$ martensite. During the detwining step described here, each lattice correspondence variant of $\gamma_{1}^{\prime}$ in the twin will change into two certain lattice correspondence of $\beta_{1}^{\prime}$ martensite. So there are $96 \times 2=192$ possible solutions for the transformation strain in $\beta_{1}^{\prime}$ martensite. For a more detailed discussion, please refer to the paper by Zhang et al (2000).

\section{Driving force}

The driving force is an energy differential that drives the material to transform from one phase to another. The energy includes the chemical free energy, the mechanical energy, the magnetic energy and the electric energy, etc. The energy differential can be induced by variation of temperature, applied stress, applied magnetic field, applied electric field or by a combination of all these forces. For example, in most SMAs, the phase transformation from austenite to martensite can be induced by cooling or by applied stresses, and from one martensitic variant to another by applied stress and from martensite to austenite by heating. In magnetostrictive materials, such as $(\mathrm{Tb}, \mathrm{Dy}) \mathrm{Fe}_{2}$ and $\mathrm{Ni}_{2} \mathrm{MnGa}$, applied stress and an applied magnetic field will drive the materials to transform from the parent phase to martensite, or from one martensite to another (James and Wutting 1998, Newnham 1998). And in piezoelectric and electrostrictive materials, such as $\mathrm{Pb}(\mathrm{Zr}, \mathrm{Ti}) \mathrm{O}_{3}$ and $\mathrm{Pb}(\mathrm{Mg}, \mathrm{Nb}) \mathrm{O}_{3}$, the phase transformation can be induced by the electromechanical-coupling force (Newnham 1998). In this paper, we focus on the driving forces of the phase transformation under applied stresses.

\subsection{The maximum resolved shear stress criterion}

The resolved shear stress (RSS) is a concept which is often used in the plastic slip of single-crystal metals (Smallman 1985, Callister 1994). Since the martensitic transformation is accompanied by a shear-like deformation, the RSS has been used by many authors as the driving force for the phase transformation (Oishi and Brown 1971, Okamoto et al 1986, Horikawa et al 1988, Miyazaki and Otsuka 1989). 
3.1.1. For the transformation from $\beta_{1}$ to $\gamma_{1}^{\prime}$ (SME). In this case, there exists an invariant plane between the martensite and the parent phase. The deformation of the martensite can be represented as the combination of the habitplane normal $\boldsymbol{m}$ and a shear vector $\boldsymbol{b}$. Being similar to the slip system in single-crystal metals, the habit-plane $\boldsymbol{m}$ in SMAs works in the same way as the slip-plane in metals and the transformation shear $\boldsymbol{b}$ as the slip direction. So the resolved shear stress on the $\boldsymbol{m}_{\boldsymbol{i}}$-plane in the $\boldsymbol{b}_{\boldsymbol{i}}$ direction is

$$
\tau_{i}=\boldsymbol{m}_{i} \cdot \sigma \cdot \overline{\boldsymbol{b}}_{i}
$$

where $i$ is an integer in $\{1,2, \ldots, 96\}$ and $\bar{b}$ is a unit vector defined as $\overline{\boldsymbol{b}}_{i}=\boldsymbol{b}_{i} /\left|\boldsymbol{b}_{i}\right|$ and $\sigma$ is the applied stress. There is no summation of the index $i$ in equation (12) nor in the following equations.

For a given applied stress, the RSS on all the 96 habitplane variants can be calculated. Here we give the results for the simplest uniaxial loading in all possible loading axis orientations with respect to the parent phase lattice. In a uniaxial state, the stress can be written as

$$
\sigma=t e \otimes e
$$

where $e$ is the loading direction and $t$ is the magnitude of the stress. Substituting equation (13) into equation (12) and setting $t$ as \pm 1 , the RSS for a unit uniaxial stress is

$$
\tau_{i}= \pm\left(m_{i} \cdot e\right)\left(e \cdot \bar{b}_{i}\right)= \pm\left(m_{i} \cdot e\right)\left(e \cdot b_{i}\right) /\left|b_{i}\right|
$$

where $t=1$ is tensile stress and $t=-1$ is compressive stress. $\tau_{i}$ was calculated for all 96 variants and the largest one in each loading direction was set as $\tau^{\max }$. The maximum resolved shear stresses $\tau^{\max }$ under uniaxial loading in different directions are shown in figure 5. The left-hand figure is under tension and the right-hand figure is under compression. Figure 6 illustrates the corresponding variant pair which has the largest RSS under uniaxial loads. The distribution of the variant pairs near $(001),(00 \overline{1}),(100),(\overline{1} 00),(010)$ and $(0 \overline{1} 0)$ poles are listed in the table to the right of figure. In figure 6 and the table the numbers in the brackets represent the lattice correspondence variant pair with the first number for the major variant in the twin. The subscripts I and II represent type-I and type-II twins, respectively. The variant pairs with and without the asterisk are, respectively, the two solutions of equation (6) for a twin pair $\left(f, \boldsymbol{a}_{i}, \boldsymbol{n}_{i}\right)$.

From figure 6 we can see that the most possible variant pairs under tension are those with a type-I twin. Only when the loading directions are near the (100), (010) and (001) poles, is it possible to induce the variants with a type-II twin as shown in the table. In contrast, the most favorable variants are those with a type-II twin under compression, variants with a type-I twin only appear near the three principal lattice axes (figure 6(b) and its table).

Under uniaxial loading, the deformation along the loading direction is

$$
E=e \cdot \varepsilon^{t} \cdot e
$$

where $\varepsilon^{t}$ is the transformation strain of the martensitic variants. This transformation strain can be written in terms of $\boldsymbol{m}$ and $\boldsymbol{b}$ as

$$
\varepsilon^{t}=\frac{1}{2}\left(\boldsymbol{F}^{T} \cdot \boldsymbol{F}-\boldsymbol{I}\right)
$$
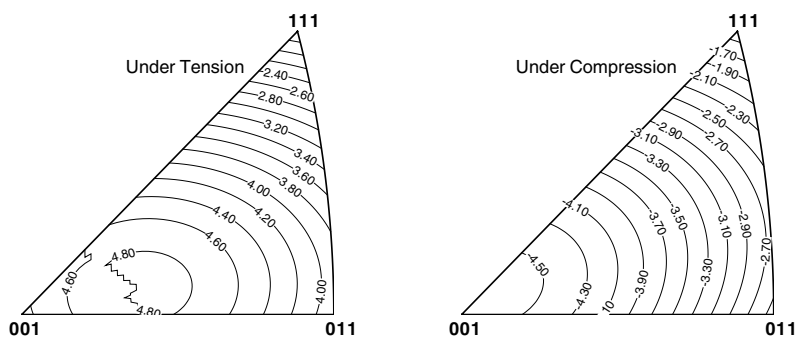

Figure 7. Contours of the transformation strains under different uniaxial stresses in the SME case.
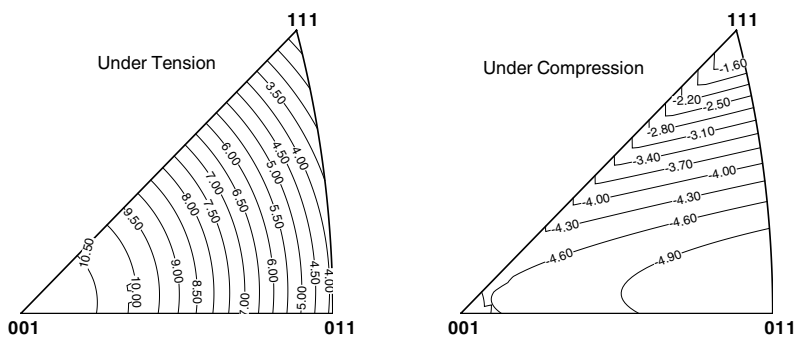

Figure 8. Contours of the transformation strains under different uniaxial stresses in the SE case.
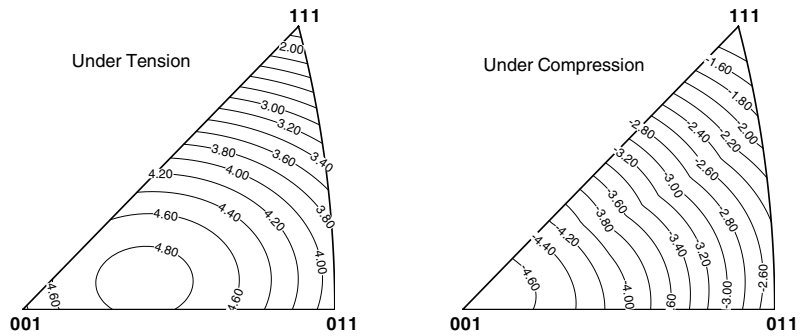

Figure 9. Contours of maximum work and transformation strains under uniaxial stresses in different directions (for type-I variants).
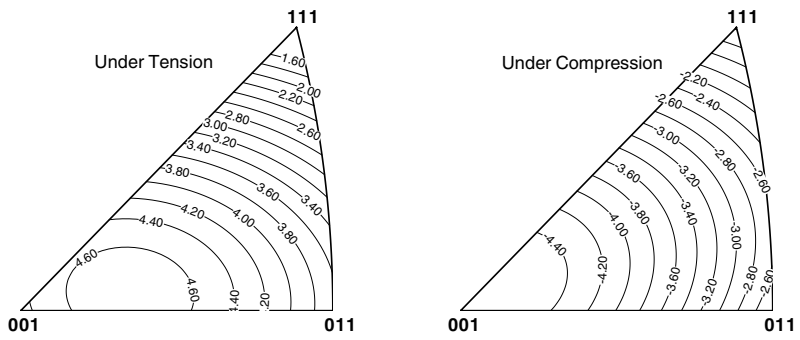

Figure 10. Contours of maximum work and transformation strains under uniaxial stresses in different directions (for type-II variants).

or

$$
\varepsilon^{t}=\frac{1}{2}[\boldsymbol{m} \otimes \boldsymbol{b}+\boldsymbol{b} \otimes \boldsymbol{m}+(\boldsymbol{b} \cdot \boldsymbol{b}) \boldsymbol{m} \otimes \boldsymbol{m}]
$$

where $\boldsymbol{F}$ is $\boldsymbol{F}^{M}$ given by equations (3), (7) or (8). So equation (15) is

$$
E=(\boldsymbol{m} \cdot e)(\boldsymbol{b} \cdot \boldsymbol{e})+\frac{1}{2}(\boldsymbol{b} \cdot \boldsymbol{b})(\boldsymbol{m} \cdot \boldsymbol{e})^{2} .
$$

Under a uniaxial stress, the deformation $E$ was calculated by using the $(\boldsymbol{m}, \boldsymbol{b})$ of the most favorable variant. The orientation dependence of $E$ is illustrated in the stereographic projection in figure 7 . 


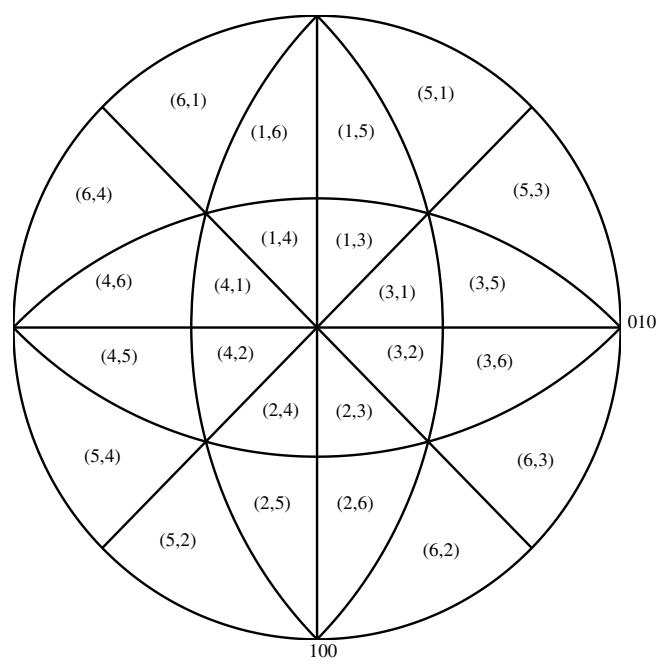

(a)
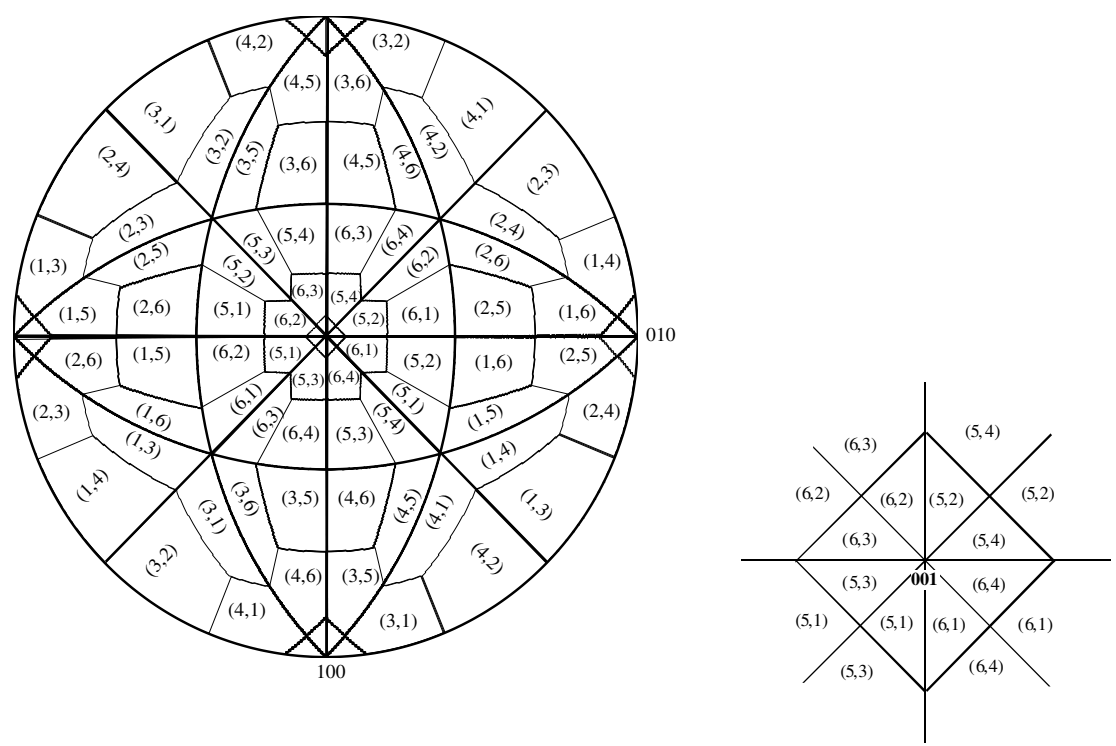

(b)

Figure 11. The most favorable type-I twin variants under uniaxial stresses in different directions using maximum work criterion (for the SME case): (a) under tension; (b) under compression.

3.1.2. For the transformation from $\boldsymbol{\beta}_{\mathbf{1}}$ to $\boldsymbol{\beta}_{\mathbf{1}}^{\prime}(\mathrm{SE})$. The previously described RSSs are on the habit-planes of $\gamma_{1}^{\prime}$ martensite. Since the transformation strain of $\beta_{1}^{\prime}$ martensite cannot be decomposed into two components (a habit-plane normal and a shear vector), we cannot calculate the RSSs directly for the deformation of $\beta_{1}^{\prime}$ martensite. But, as we have suggested in section 2, the $\beta_{1}^{\prime}$ martensite comes from a corresponding $\gamma_{1}^{\prime}$ martensite via the three steps of detwinning, distorting and slip. Thus the preferred $\beta_{1}^{\prime}$ martensitic variant for a given applied stress can be determined by the RSS for the deformation of the $\gamma_{1}^{\prime}$ martensite. Since the directions of the $\mathrm{A}-\mathrm{M}$ interface in $\beta_{1}^{\prime}$ martensite are identical to the directions of the habit-plane in $\gamma_{1}^{\prime}$ martensite, results for the maximum RSS (figure 5) and the preferred variant (figure 6) are the same for both the SME and SE cases. The deformations under uniaxial stresses in different directions differ however, and these are shown in figure 8 for $\beta_{1}$ to $\beta_{1}^{\prime}$ (SE) martensitic transformation using $\boldsymbol{G}^{M}$ from equation (10) in place of $\boldsymbol{F}$ in equation (16a). From figure 8 we can see the SE exhibits great tension-compression asymmetry in this material, whereas, in the SME case, the asymmetry is small.

\subsection{The maximum transformation work criterion}

The maximum transformation work done by the applied stress on the transformation strain is a comprehensive driving force which has been widely used in many constitutive models (Patoor et al 1993, 1994, Bekker and Brinson 1997, Goo and Lexcellent 1997, Lu and Wang 1997, Huang and Bunsen 1998). It was also used as a variant selection rule in some literature (Chu 1993, Shield 1995).

3.2.1. For the transformation from $\boldsymbol{\beta}_{1}$ to $\gamma_{1}^{\prime}$ (SME). In this case the work done on the transformation strain $\varepsilon_{i}^{t}$ by the applied stress, $\sigma$, is

$$
W_{i}=\sigma \cdot \varepsilon_{i}^{t}
$$




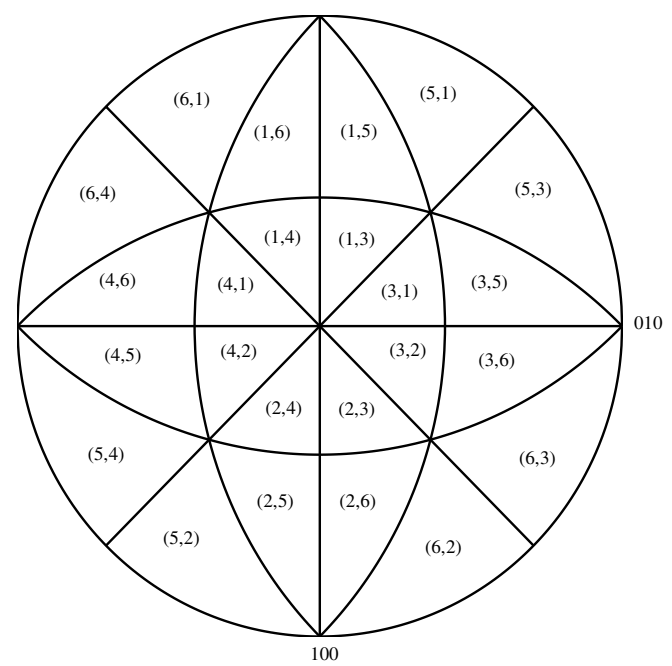

(a)

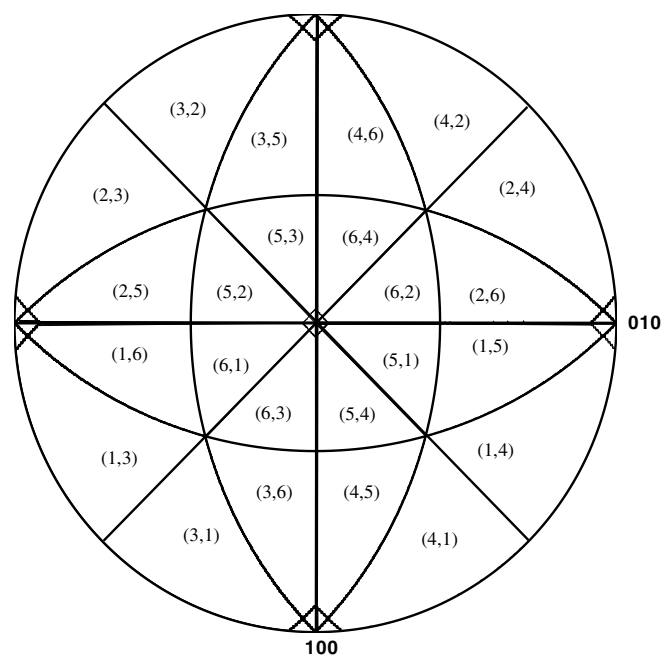

(b)

Figure 12. The most favorable type-II twin variants under uniaxial stresses in different directions using the maximum work criterion (for the SME case): (a) under tension; (b) under compression.

where $\varepsilon_{i}^{t}$ is calculated by equation (16) and $i$ is an integer in $\{1,2, \ldots, 96\}$.

Again we give the results for uniaxial loading in all possible orientations with respect to the parent phase lattice. In this case, the work is

$$
W_{i}=t e \cdot \varepsilon_{i}^{t} \cdot e
$$

Substituting equation (16) into equation (19), the work can be further written as

$$
W_{i}=t\left[(\boldsymbol{m} \cdot \boldsymbol{e})(\boldsymbol{b} \cdot \boldsymbol{e})+\frac{1}{2}(\boldsymbol{b} \cdot \boldsymbol{b})(\boldsymbol{m} \cdot \boldsymbol{e})^{2}\right] .
$$

For the unit tensile and compressive stresses (with $t= \pm 1$ respectively) in all orientations, $W_{i}$ was calculated for all 96 $\gamma_{1}^{\prime}$ martensitic phases. The largest one in each orientation was set as $\boldsymbol{W}^{\max }$.

The calculation determines that $\boldsymbol{W}^{\max }$ in every case is associated with variants of the type-I twin. The larger transformation shear $\boldsymbol{b}$ of the type-I twin variants is responsible for this result $\left(\left|\boldsymbol{b}^{I}\right|=0.0958,\left|\boldsymbol{b}^{I I}\right|=0.0932\right)$.

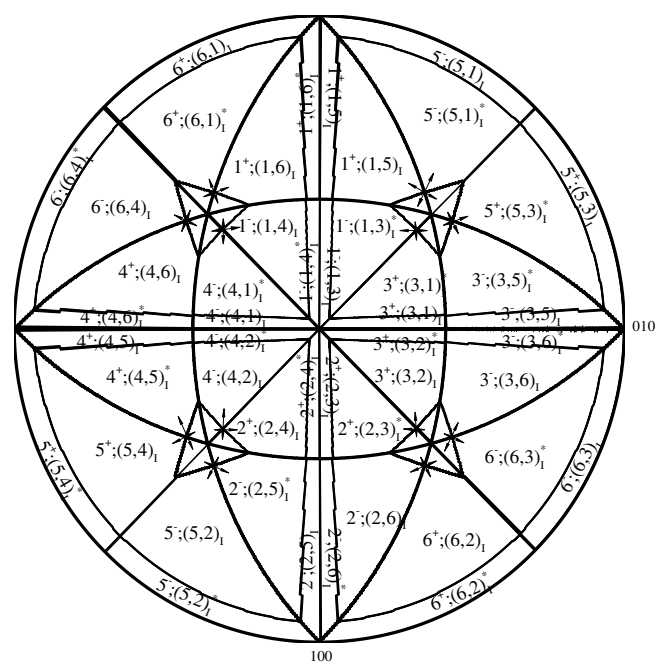

(a)

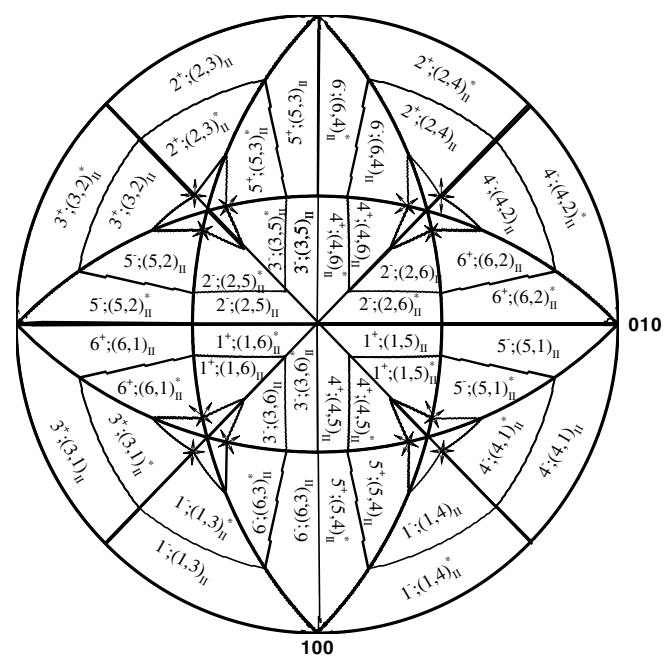

(b)

Figure 13. The most favorable variants under uniaxial stresses in different directions using the maximum work (for the SE case): (a) under tension; (b) under compression.
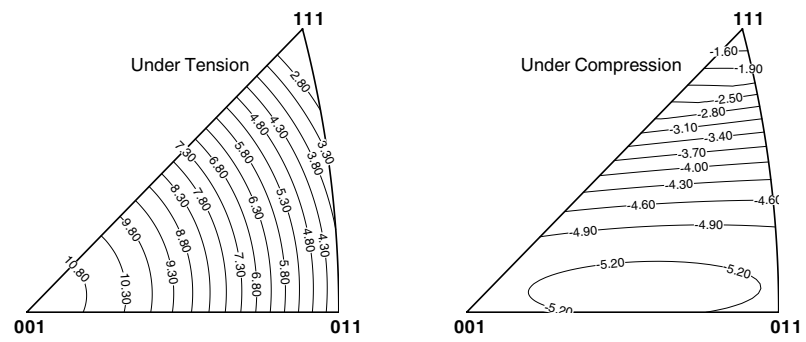

Figure 14. Contours of the transformation strains under different uniaxial stresses in the SE case.

Thus using work as the phase transformation criterion and assuming that all 96 variants have the same resistance force $W_{C R}$, it is impossible for the 48 type-II twin variants to appear under the applied stress. But in many experiments variants with a type-II twin were observed (Ichinose et al 1985, Okamoto et al 1986, Shield 1995). It was also found that the type-I twins are 2.5 times harder to move than the type-II twins in some materials (Ichinose et al 1991). For 
Table 1. Comparison between uniaxial tension tests and theoretical calculation. Orientation of the samples are shown in figure 15.

\begin{tabular}{llll}
\hline Specimens & S1(SME) & S2(SME) & S3(SE) \\
\hline Uniaxial tension & Habit-plane normal: & Habit-plane in $x-y$ plane: & A-M interface in $x-y$ plane: \\
experiments & $(-0.403,-0.639,-0.653)$ & $55.5^{\circ}$ & $52.3^{\circ}$ \\
& $\left(\varepsilon_{x}, \varepsilon_{y}, \varepsilon_{z}, \varepsilon_{x y}, \varepsilon_{y z}\right):$ & $\left(\varepsilon_{x}, \varepsilon_{y}, \varepsilon_{x y}\right):$ & $\left(\varepsilon_{x}, \varepsilon_{y}, \varepsilon_{x y}\right):$ \\
& $(-0.99,4.46,-3.05,-0.66,-0.84)$ & $(-4.07,3.70,-1.38)$ & $(-6.37,5.90,-1.17)$ \\
Theoretical calculation & Habit-plane normal: & Habit plane in $x-y$ plane: & A-M interface in $x-y$ plane: \\
which is most & $(-0.444,-0.617,-0.652)$ & $57.6^{\circ}$ & $54.2^{\circ}$ \\
consistent with the & $\left(\varepsilon_{x}, \varepsilon_{y}, \varepsilon_{z}, \varepsilon_{x y}, \varepsilon_{y z}\right):$ & $\left(\varepsilon_{x}, \varepsilon_{y}, \varepsilon_{x y}\right):$ & $\left(\varepsilon_{x}, \varepsilon_{y}, \varepsilon_{x y}\right):$ \\
experiments & $(-1.01,4.53,-3.39,-0.92,-0.79)$ & $(-4.24,3.82,-1.66)$ & $(-4.30,5.76,-1.96)$ \\
& Lattice correspondence & Lattice correspondence & Lattice correspondence \\
& variant pair: $(6,2)_{I I}^{*}$ & variant pair: $(6,4)_{I I}^{*}$ & Variant: $6 ;(6,4)_{I}$ \\
Corresponding RSS & Third largest overall & Third largest overall & - \\
& Type-II largest & Type-II largest & \\
Corresponding work & Third largest overall & Third largest overall & Largest \\
& Type-II largest & Type-II largest & \\
\hline
\end{tabular}

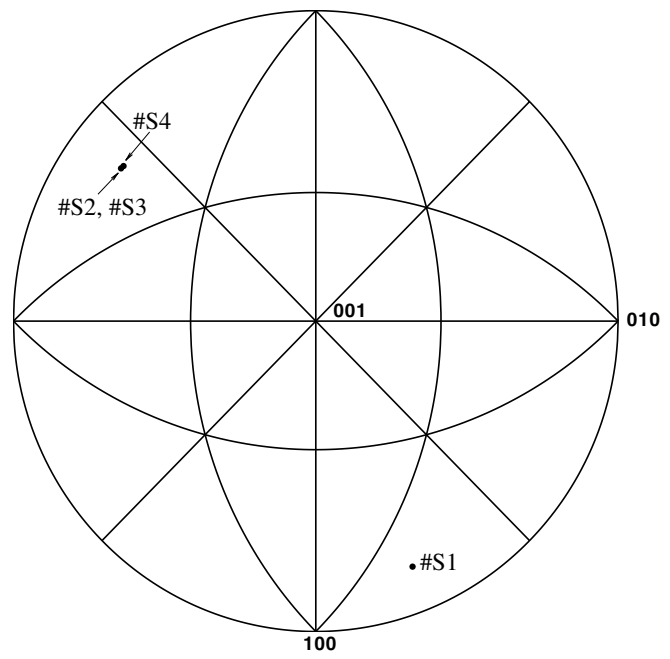

Figure 15. The orientation of the samples: uniaxial load applied in this direction.

this reason, we give the results for type-I and type-II twins separately. Figure 9 is the $W^{\max }$ as a function of the uniaxial stress orientation for type-I twin variants and figure 10 is for type-II twin variants. Comparing equation (17) with equation (20) we can see that the work $W_{i}$ done by the applied uniaxial stress on the variant $\left(\boldsymbol{m}_{i}, \boldsymbol{b}_{i}\right)$ has the same form as the uniaxial transformation strain of $\left(\boldsymbol{m}_{i}, \boldsymbol{b}_{i}\right)$. So figures 9 and 10 also provide the strain distribution under different uniaxial loads for type-I twin variants and type-II twin variants respectively. When the figures represent the contour of maximum work, the labeled values are $100 \mathrm{~W}^{\text {max }}$; when they represent the contour of strain, the values are strain (\%). The most favorable variants for type-I and type-II twins are shown in figures 11 and 12, respectively. In all the figures, (a) is under tension and (b) is under compression. The small triangle domains near the principal lattice axes in figures 11(b) and 12(b) are not labeled explicitly. The variant pairs in these domains can be found by the following rule: the variant pair in a small triangle domain is the same as that in its diagonally opposite domain. Some examples were given in the figure beside figure 11(b).
3.2.2. For the transformation from $\beta_{1}$ to $\beta_{1}^{\prime}(\mathrm{SE})$. In this case, the deformation gradient $G^{M}$ in equation (10) was substituted into equation (16a) (replacing $\boldsymbol{F}$ by $\boldsymbol{G}^{M}$ ) to calculate the transformation strain, and then to calculate the work by using equation (18). The variants which have the largest work under uniaxial loads are shown in figure 13. In this figure the label $1^{+} ;(1,6)_{I I}^{*}$, for example, means that the final variant under the uniaxial load is $1^{+}$ (where $1^{+}, 1^{-}, 2^{+}, 2^{-}, \ldots$, and $6^{+}, 6^{-}$represent the 12 lattice correspondence variants in $\beta_{1}^{\prime}$ martensite) and the normal of the A-M interface is the same as the habit-plane normal of variant pair $(1,6)_{I I}^{*}$. Double-headed arrows indicate that the two domains are occupied by the same variant. The corresponding strain distributions are shown in figure 14.

\section{Comparison with experiments}

\subsection{Uniaxial tension tests}

The experimental data were obtained from moiré tests for three different samples (Zhang et al 1999, 2000). The specimen orientations (i.e. the loading direction) are marked with the symbols in figure 15 . The samples S1 and S2 are both in the SME case (the $A_{s}$ point of the specimens is higher than the room temperature) but their orientations are different. The sample S3 is in the SE case and has the same orientation as that of S2. The comparison between the experiments and the theoretical calculations are listed in table 1 . The data in the first row are the experimental results including the directions of the observed habit-plane (or A-M interface) and the components of strain. The second row shows the theoretical calculations for the variant most consistent with the experiments. These variants are selected by comprehensively comparing the habit-plane normal and transformation strain calculated from known lattice parameters (e.g. figure 3 and equation (16b)) with the experimental results, without reference to the maximum RSS or work. The ranks of the RSS and the maximum work for the variants in the second row are indicated in the third and fourth rows, respectively.

The variant chosen by each criterion can be found by comparison of figure 15 with earlier figures. For RSS, figure 6 indicates that sample S1 (SME) would have $(6,2)_{I}^{*}$ 
Table 2. Comparison between uniaxial compression test and theoretical calculation (SME case).

\begin{tabular}{llll}
\hline Experimental results & Theoretical calculation & Corresponding RSS & Corresponding work \\
\hline Habit-plane in $x-y$ plane: $-73.6^{\circ}$ & Habit-plane in $x-y$ plane: $-66.0^{\circ}$ & Fourth largest & Type-I largest \\
Twin-plane in $x-y$ plane: $-12.8^{\circ}$ & Twin-plane in $x-y$ plane: $-11.4^{\circ}$ & & \\
& Variant pair: $(2,4)_{I}^{*}$ & & \\
\hline
\end{tabular}

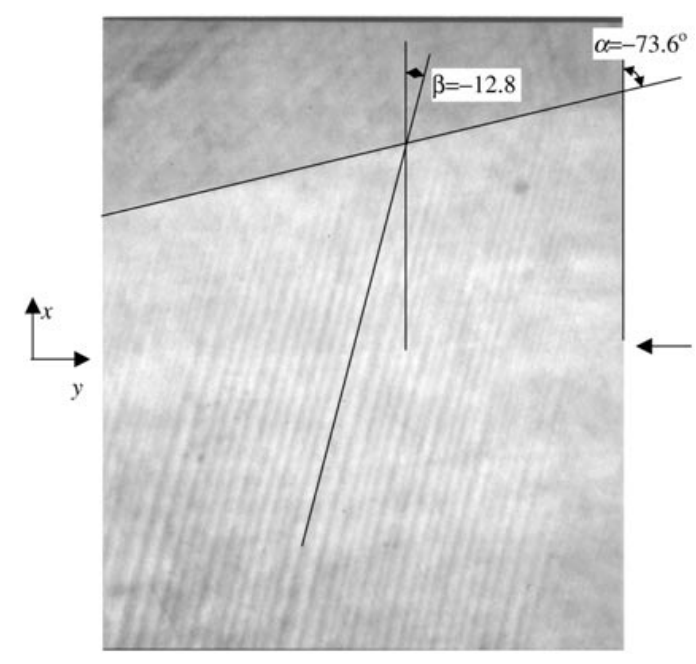

Figure 16. An SEM picture of the habit-plane and twin-plane for uniaxial compression on sample S4.

and samples S2 (SME) and S3 would have $(6,4)_{I}^{*}$ activated, as these are the variants with the largest RSS when loaded in the given direction. The experimental results show different variants active in these cases. As shown in table 1 the active variant for sample $\mathrm{S} 1$ is $(6,2)_{I I}^{*}$ and for sample $\mathrm{S} 2$ is $(6,4)_{I I}^{*}$. Both of these have the third largest RSS overall, but the largest RSS among the type-II variants. A similar result is found for the maximum transformation work criterion. For SE, the applicability of the RSS criterion is questionable since the deformation cannot be represented simply by the habit-plane normal and shear; however, the maximum transformation work criterion is easily applied and the variant selected by the criterion for SE was the experimentally observed variant: for $\mathrm{S} 3$ figure 13(a) indicates $6^{-}(6,4)_{I}$ had the largest transformation work and this is the variant seen experimentally.

\subsection{Uniaxial compression test}

A uniaxial compression test was performed by a real-time loading stage in SEM. The orientation of the sample is marked in figure 15 (sample S4). The habit-plane and the twinplane of the stress-induced martensite in one surface were obtained (figure 16). The comparisons with the theoretical calculations are listed in table 2. From the table we can see that the largest work for the type-I twin variants can be used as a variant selection rule when the variants are induced by compression loads.

\section{Discussion and conclusions}

Two kinds of martensitic transformation in CuAlNi singlecrystal SMA have been analyzed in the present work. For the $\beta_{1} \rightarrow \gamma_{1}^{\prime}$ transformation in the SME case, the habitplane normals and transformation strains are predicted using the CTM model (Ball and James 1987); for the $\beta_{1} \rightarrow \beta_{1}^{\prime}$ transformation in the SE case, the directions of the noninvariant $\mathrm{A}-\mathrm{M}$ interface and the transformation strains are obtained using our non-invariant-plane model (Zhang et al 2000). Under uniaxial tension and compression stresses, the resolved shear stress (RSS) on habit-plane variants and the work done on the transformation strains are calculated. These two indices are used to select the most favorable variants under applied stresses and the results are compared with experimental measurements. The following conclusions have been obtained:

1. Work is a better variant selection criterion than the RSS. In contrast to plastic slip in a single-crystal metal, the transformation shear in martensite is not in the habit-plane, because of a small but significant volume dilation during the martensitic transformation. Thus the RSS criterion cannot provide a complete force for the transformation while work is a comprehensive driving force from a thermodynamic point of view. Work plays a more precise role in selecting the most favorable variant under a certain applied stress than the RSS though the difference between them is small.

2. In the SME case, the maximum transformation work is on the variant with a type-I twin under uniaxial tension stress; and under uniaxial compression stress, the maximum transformation work is on the typeII twin variant. However, experiments demonstrate that most of the tension-stress-induced variants are of the type-II twin (Ichinose et al 1985, Okamoto et al 1986, Shield 1995, Zhang et al 1999, 2000). The experimental results in the present work indicate that the compression-stress-induced variants are of the typeI twin. These contradictory results may be due to the different mobility of the two types of twin. Ichinose et al (1991) reported that type-I twins are 2.5 times harder to move than type-II twins in some materials. So we treat the type-I twin variants and type-II twin variants separately. Comparison between the experimental results and theoretical calculations show that the type-II twin variants are more favorable than type-I twin variants under uniaxial tension; and under uniaxial compression the type-I twin variants are more favorable.

From the work here, we can propose the following hypothesis: if $\sigma_{k k}>0$, then type-II twin variants are active; while if $\sigma_{k k} \leqslant 0$, then type-I twin variants are active. This hypothesis needs to be tested with additional experiments; in particular, those with more complex load states (non-uniaxial loading).

3. In the SE case, work is always valid for selecting the stress-induced variant. 
4. Tension-compression asymmetry. According to the calculation, this material shows great tensioncompression asymmetry in both aspects of the transformation strain and the most favorable variants. The experimental results and theoretical calculations confirm that the asymmetry is due to different active variants under the different loading modes. Understanding and being able to model this property is important for SMA device design.

\section{Acknowledgment}

The authors wish to recognize the National Science Foundation for sponsorship of this work.

\section{References}

Ball J M and James R D 1987 Fine phase mixtures and minimizers of energy Arch. Rat. Mech. Anal. 100 13-52

Bekker A and Brinson L C 1997 Thermo-induced transformation in a prestressed 1-DSMA polycrystalline body: phase diagram kinetics approach J. Mech. Phys. Solids. 45 949-88

Bhattacharya K 1991 Wedge-like microstructures in martensites Acta Metall. 39 2431-44

1992 Self-accomadation in martensite Arch. Rat. Mech. Anal. 120 201-44

Bowles J S and Mackenzie J K 1954 The crystallography of martensitic transformation I and II Acta Metall. 2 129-47

Boyd J G and Lagoudas D C 1994 Thermomechanical response of shape memory composites J. Intell. Mater. Syst. Struct. 5 333-46

Callister W D 1994 Materials Science and Engineering: An Introduction (New York: Wiley)

Chu C H 1993 Hysteresis and microstructures: a study of biaxial loading on compound twins of copper-aluminum-nickel single crystals PhD Thesis Department of Aerospace Engineering and Mechanics, University of Minnesota

Funakubo H (ed) 1984 Precision machinery and robotics Shape Memory Alloys (New York: Gordon and Breach)

Gao X and Brinson L C 2000 A simplified multivariant SMA model based on invariant plane nature of martensitic transformation J. Eng. Mater. Tech. submitted

Goo B C and Lexcellent C 1997 Micromechanics-based modelling of two-way memory effect of a single crystalline shape memory alloy Acta Mater. 45 727-37

Horikawa H, Ichinose S, Morii K, Miyazaki S and Otsuka K 1988 Orientation dependence of $b_{1}^{\prime}$ stress-induced martensite transformation in a CuAlNi alloy Metall. Trans. A 19 915-23

Huang M S and Brinson L C 1998 A multivariant model for single crystal shape memory alloy behavior J. Mech. Phys. Solids 46 1379-409

Ichinose S, Funatsu Y, Otani N, Ichikawa T and Miyazaki S 1991 Deformation modes of $2 \mathrm{H}$ type martensitic single crystals in $(\mathrm{Cu}, \mathrm{Ni})_{3} \mathrm{Al}$ alloy Int. Symp. Intermetallic Compounds (Sendai, Japan) pp 263-6

Ichinose S, Funatsu Y and Otsuka K 1985 Type II deformation twinning in $\mathrm{g}_{1}^{\prime}$ martensite in a CuAlNi alloy Acta Metall. 33 1613-20

James R D and Wutting M 1998 Magnetostriction of martensite Phil. Mag. A 77 1273-99

Khachaturyan A G 1983 Theory of Structural Transformations in Solids (New York: Wiley)

Liang C and Rogers C A 1990 One-dimensional thermomechanical constitutive relations for shape memory materials J. Intell. Mater. Syst. Struct. 1 207-34 1992 A multi-dimensional constitutive relations for shape memory alloys J. Eng. Math. 26 429-43
Lu Z K and Weng G J 1997 Martensitic transformation and stress-strain relations of shape memory alloys $J$. Mech. Phys. Solids 45 1905-28

Miyazaki S and Otsuka K 1989 Development of shape memory alloys IJSS Int. 29 353-77

Newnham R E 1998 Phase transformations in smart materials Acta Crystallogr. A $\mathbf{5 4} 729-37$

Oishi K and Brown C 1971 Stress-induced martensite formation in CuAlNi alloys Metall. Trans. 2 1971-7

Okamoto K, Ichinose S, Morii K, Otsuka K and Shimizu K 1986 Crystallography of $\mathrm{b}_{1}$ to $\mathrm{g}_{1}^{\prime}$ stress-induced martensitic transformation in a CuAINi alloy Acta Metall. 34 2065-73

Otsuka K, Nakamura T and Shimizu K 1974 Electron microscopy study of stress-induced acicular $\mathrm{b}_{1}^{\prime}$ martensite in $\mathrm{CuAlNi}$ alloy Trans. JIM 1974 201-10

Otsuka K, Sakamoto H and Shimizu K 1976 Two stage superelasticity associated with successive martensite to martensite transformations Scr. Metall. 10 983-8

-1979 Successive stress-induced martensite transformation and associated transformation pseudoelasticity in $\mathrm{CuAlNi}$ alloys Acta Metall. 27 585-601

Otsuka K and Shimizu K 1969 Morphology and crystallography of thermoelastic g' CuAlNi martensite Japan. J. Appl. Phys. 8 1196-204

- 1974a Morphology and crystallography of thermoelastic $\mathrm{g}_{1}^{\prime}$ CuAlNi martensite analyzed by the phenomenological theory Acta Metall. 1974 103-8

_ 1974b Twinning in $\mathrm{g}^{\prime} \mathrm{CuAlNi}$ martensite with $\mathrm{Cu}_{3}$ Ti type ordered structure Trans. JIM 15 109-13

Patoor E, Eberhardt A and Berveiller M 1993 Micromechanical modelling of superelasticity in shape memory alloys Pitman Res. Notes Math. Series $29638-54$

-1994 Micromechanical modelling of the shape memory behavior ASME Mechanics of Phase Transformations and Shape Memory Alloys ed L C Brinson and B Moran (New York: The American Society of Mechanical Engineers) pp 23-37

Saburi T and Nenno S 1981 Shape memory effect and related phenomena Int. Conf. on Solid-Solid Phase Transformation ed H I Aaroson et al (Pittsburgh, PA) pp 1455-79

Sato Y and Tanaka K 1988 Estimation of energy dissipation in alloys due to stress-induced martensitic transformation Res. Mech. 23 381-93

Shield T W 1995 Orientation dependence of the pseudoelastic behavior of single crystal of CuAlNi in tension J. Mech. Phys. Solids 43 869-95

Smallman R E 1985 Morden Physical Metallurgy (London: Butterworths)

Sun Q P and Hwang K C 1993a Micromechanics modeling for the constitutive behavior of polycrystalline shape memory alloys-I. Derivation of general relations J. Mech. Phys. Solids $411-17$

- 1993b Micromechanics modeling for the constitutive behavior of polycrystalline shape memory alloys-II. Study of the individual phenomena J. Mech. Phys. Solids 41 19-33

Sun Q P, Xu T and Zhang X Y 1999a On deformation of A-M interface in single crystal shape memory alloys and some related issues J. Eng. Mater. Tech. 121 38-43

Sun Q P, Zhang X Y and Xu T 1999b Some recent advances in experimental study of shape memory alloys Solid Mechanics and its Applications 62 407-16

Wechsler M S, Lieberman D S and Read T A 1953 On the theory of formation of martensite Trans. AIME 197 1503-15

Zhang X Y, Sun Q P and Yu S W 1999 On the strain jump in shape memory alloys-a crystallographic-based mechanics analysis Acta Mech. Sinica 15 134-44

2000 A non-invariant-plane model for the interface in CuAlNi single crystal shape memory alloys J. Mech. Phys. Solids 48 2163-82

Zhang X Y, Xu T, Sun Q P and Pin T 1998 On the full-field deformation of single crystal shape memory alloys-stress-induced $b_{1}$ to $g_{1}^{\prime}$ martensitic transformation J. Physique IV 7 C5 555-60 